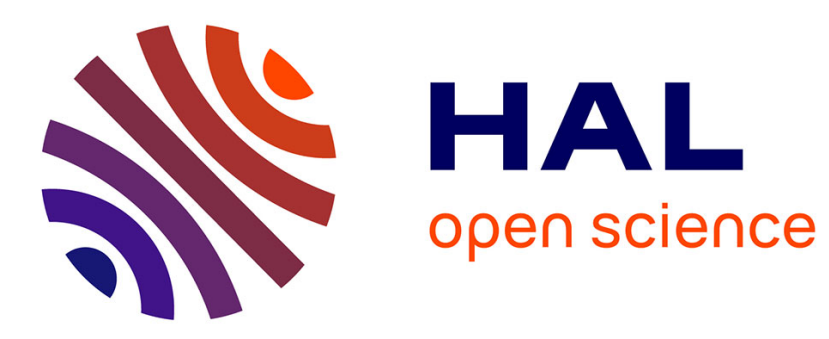

\title{
A solution to the stick slip problem for an electropneumatic drive
}

Karima Turki, Mohamed Smaoui, Daniel Thomasset, Xavier Brun

\section{To cite this version:}

Karima Turki, Mohamed Smaoui, Daniel Thomasset, Xavier Brun. A solution to the stick slip problem for an electropneumatic drive. International Journal of Fluid Power, 2011, 12 (1), pp.19-29. hal00799141

\section{HAL Id: hal-00799141 https://hal.science/hal-00799141}

Submitted on 16 Apr 2019

HAL is a multi-disciplinary open access archive for the deposit and dissemination of scientific research documents, whether they are published or not. The documents may come from teaching and research institutions in France or abroad, or from public or private research centers.

$$
\text { Copyright }
$$

L'archive ouverte pluridisciplinaire HAL, est destinée au dépôt et à la diffusion de documents scientifiques de niveau recherche, publiés ou non, émanant des établissements d'enseignement et de recherche français ou étrangers, des laboratoires publics ou privés. 


\title{
A SOLUTION TO THE "STICK-SLIP" PROBLEM FOR AN ELECTROPNEUMATIC DRIVE
}

\author{
K. TURKI*. M. SMAOUI*. D. THOMASSET*. X. BRUN*. \\ * Université de Lyon, Laboratoire Ampère UMR CNRS 5005, Institut National des Sciences Appliquées \\ de Lyon, FRANCE \\ (Tel: +334 724360 33; e-mail:karima.turki@insa-lyon.fr
}

\begin{abstract}
This paper describes a solution to the problem of «stick-slip» for an electropneumatic system. The phenomenon of «stick-slip» may appear during the mechanical static state when the position is fixed but the pressures continue to evolve in each actuators chambers, until exceeding the dry friction zone. The system is then in partial equilibrium. The idea to avoid this phenomenon is a switching control law between the tracking position control and the pressure regulation.
\end{abstract}

Keywords: "Stick-slip" phenomenon, electropneumatic system, switching control, experimental results.

\section{$1 \quad$ Introduction}

"Stick-slip" refers to the phenomenon of a spontaneous jerking motion that can occur while two objects are sliding over each other. Stick-slip is caused by the surfaces alternating between sticking to each other and sliding over each other, with a corresponding change in the force of friction. Typically, the stiction friction coefficient between two surfaces is larger than the Coulomb friction coefficient. If an applied force is large enough to overcome the stiction friction, then the reduction of the friction to the Coulomb friction can cause a sudden jump in the velocity of the movement. Examples of stick-slip can be heard from hydraulic cylinders, honing machines etc. Special chemicals can be added to the hydraulic fluid or the cooling fluid to overcome or minimize the stick-slip effect. Stick-slip is also experienced in lathes, mill centres and other machinery where something slides on a slideway. Slideway oil typically lists "prevention of stick-slip" as one of its features.

The "stick-slip" phenomenon is a real problem for the industrial development of pneumatic technology. However there are no industrial or scientific research works in the literature which present a solution that can be generalized for certain fields or in every fluid power process to eliminate this phenomenon. Only some specific empirical solutions have been tested in specific contexts to reduce the possibility of the occurrence of the "stick-slip" phenomenon. Cite for example: Control Engineering Staff (2003) have proposed a technological improvement by developing specific valves. Ming-Chang and Shy-I (1995) have used specific control laws to reduce the effect of friction in electropneumatic applications by using, for example, control laws with velocity or acceleration tracking trajectories. Brun, Sesmat, Thomasset and Scavarda (2005) have presented the necessary and sufficient conditions not to have the restarting phenomenon and gave an estimation of the restarting time if the condition is not in effect. Hamiti, Voda-Besançon and Roux-Buisson (1996) have coped with the problem caused by the stickslip friction in a pneumatic system and propose a method to limit and to be eliminated in a progressive manner the stiction effect by decreasing the integral gain of the PI controllers. PAI and SHIH (2003) have designed a velocity compensator to overcome the stick-slip effect of the pneumatic-driven ultraprecision table while adding directly the velocity compensation signal to the conventional PD and Fuzzy controller. Hägglund has presented a procedure that compensates for static friction (stiction) in pneumatic control valves by adding pulses to the control signal. Renn and Liao (2004) have proposed the fuzzy-sliding mode controller at a low rotational speed of a servo-pneumatic motor with presence of the nonlinear deadband and stick- 
slip friction. In all technologies for positioning systems, its well known that the use of an integral action in the control law lead to «stick-slip» occurrence. However it will be explain in this paper that in fluid power systems, the reason of «stick-slip» appearance is fundamentally different and not due to integral action.

In this paper, a solution for the problem of «stickslip» for an electropneumatic system for tracking position trajectory will be presented. It is organized as follows; in the next section the electropneumatic system is described. Then the main idea result using two switching sets of control laws is developed. Finally experimental results are presented and compared to validate the procedure.

\section{$2 \quad$ Electropneumatic system modeling}

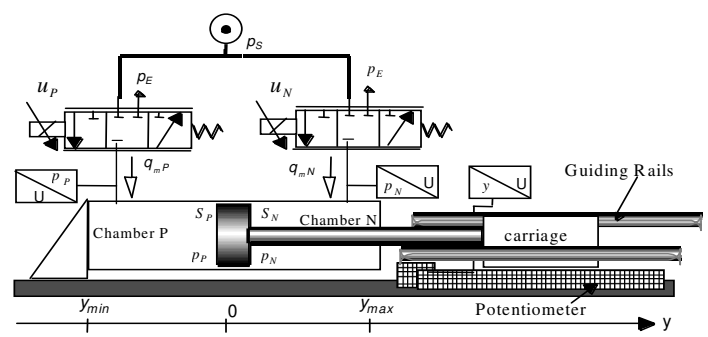

Fig.1: The electropneumatic system

The system under consideration, fig. 1, is a linear inline double acting electropneumatic servo-drive using a single rod controlled by two three-way servodistributors. The actuator rod is connected to one side of the carriage and drives an inertial load on guiding rails. The total moving mass is $17 \mathrm{~kg}$.

\subsection{Physical model}

The electropneumatic system model can be obtained using three physical laws, the mass flow rate through a restriction, the pressure behavior in a chamber with variable volume and the fundamental mechanical equation.

The pressure evolution law in a chamber with variable volume is obtained via the following assumptions Shearer (1956):

a) air is a perfect gas and its kinetic energy is negligible;

b) the pressure and the temperature are supposed to be homogeneous in each chamber;

c) the process is polytropic and characterized by the coefficient $k$.

Also the electropneumatic system model is obtained by combining all the previous relations. The two servodistributors are supposed identical and can be decomposed into a dynamic and static part (fig. 2).

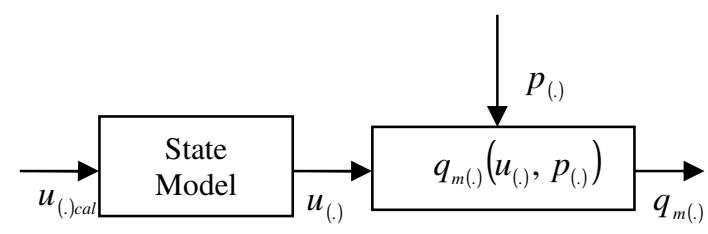

Fig.2: The dynamic and a static part of the servodistributor

In this paper, the results of Sesmat and Scavarda (1996) of the global experimental method giving the static characteristics of the flow stage have been used. The global characterization corresponds to the static measurement of the output mass flow rate $q_{m(.)}$, which depends on the input control $u_{(.)}$(fig. 3) and the output pressure $p_{(.)}$, for constant source and exhaust pressure.

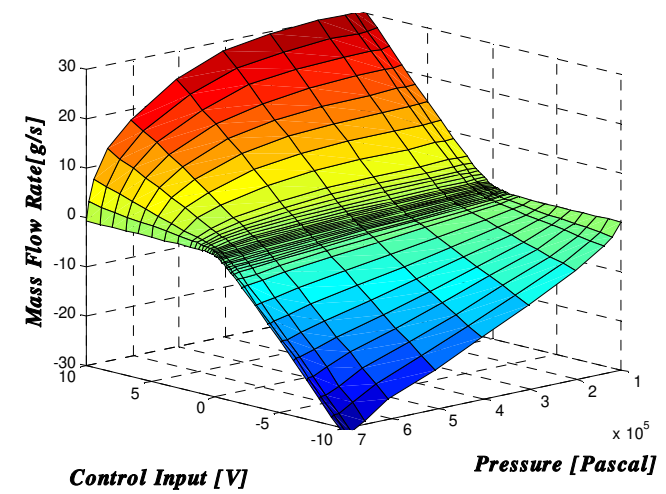

Fig. 3: The mass flow rate

The state model of the two servodistributors is given by:

$$
\begin{aligned}
& \left\{\begin{array}{l}
\frac{d \ddot{x}_{P}}{d t}=-a_{11} \ddot{x}_{P}-a_{12} \dot{x}_{P}-a_{13} x_{P}+k_{1} u_{P c a l} \\
\frac{d \dot{x}_{P}}{d t}=\ddot{x}_{P} \\
\frac{d x_{P}}{d t}=\dot{x}_{P} \\
u_{P}=x_{P}
\end{array}\right. \\
& \left\{\begin{array}{l}
\frac{d \ddot{x}_{N}}{d t}=-a_{11} \ddot{x}_{N}-a_{12} \dot{x}_{N}-a_{13} x_{N}+k_{1} u_{P c a l} \\
\frac{d \dot{x}_{N}}{d t}=\ddot{x}_{N} \\
\frac{d x_{N}}{d t}=\dot{x}_{N} \\
u_{N}=x_{N}
\end{array}\right.
\end{aligned}
$$

where $x_{(.)}$is the slide valve position.

The mechanical equation includes pressure force, viscous friction, dry friction forces and an external constant force due to atmospheric pressure. The following equations give the physical model of the actuator: 


$$
\begin{cases}\dot{y} & =v \\ \dot{v} & =\frac{1}{M}\left[S_{P} p_{P}-S_{N} p_{N}-b v-F_{f}(v)-F_{\text {ext }}\right] \\ \dot{p}_{P} & =\frac{k r T_{P}}{V_{P}(y)}\left[q_{m}\left(u_{P}, p_{P}\right)-\frac{S_{P}}{r T_{P}} p_{P} v\right] \\ T_{P}^{k} p_{P}^{k-1} & =\text { constant } \\ \dot{p}_{N} & =\frac{k r T_{N}}{V_{N}(y)}\left[q_{m N}\left(u_{N}, p_{N}\right)+\frac{S_{N}}{r T_{N}} p_{N} v\right] \\ T_{N}^{k} p_{N}^{k-1} & =\text { constant }\end{cases}
$$

where: $\left\{\begin{array}{l}V_{P}(y)=V_{P}(0)+S_{P} y \\ V_{N}(y)=V_{N}(0)-S_{N} y\end{array}\right.$

with: $\left\{\begin{array}{l}V_{p}(0)=V_{D P}+S_{P} \frac{l}{2} \\ V_{N}(0)=V_{D N}+S_{N} \frac{l}{2}\end{array}\right.$

are the piping volumes of the chambers for the zero position and $V_{D(P}$ or $\left.N\right)$ are dead volumes present at each extremity of the cylinder.

The dry friction forces $F_{f}$, which act on the moving part in the presence of viscous friction, is a nonlinear model given by several relations, for example Tustin (1947):

$$
F_{f}(v)=\left[F_{C}+\left(F_{S}-F_{C}\right) \exp (-c|v|)\right] \operatorname{sign}(v)
$$

where $F_{s}, F_{c}$ and $c$ are the stiction friction, the Coulomb friction and the Stribeck constant effect.

The function $\operatorname{sign}(v)$ is defined as follows:

$$
\begin{cases}\text { if } & v>0 \operatorname{sign}(v)=1 \\ \text { if } & v=0-1 \leq \operatorname{sign}(v) \leq 1 \\ \text { if } & v<0 \operatorname{sign}(v)=-1\end{cases}
$$

Figure 4 shows the results of the friction model for low velocities. Outside the small velocity region shown this figure, the dry friction is dominated by the constant Coulomb friction value.

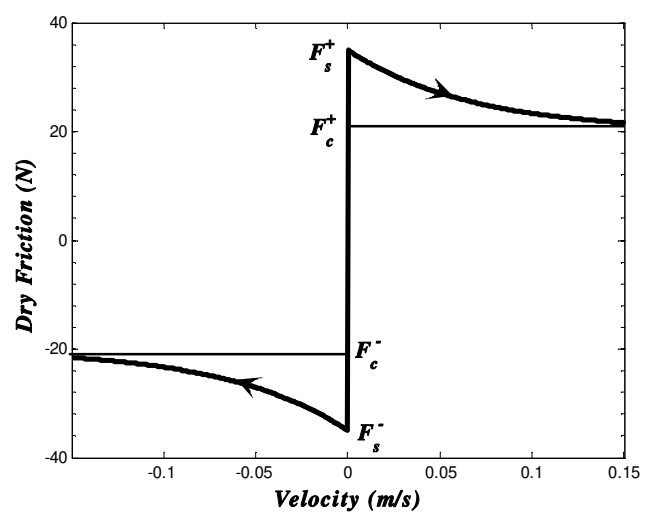

Fig. 4: Dry friction model

\section{$2.2 \quad$ Control model}

The actuator bandwith is about $10 \mathrm{~Hz}$ and the servodistributor bandwith is about $200 \mathrm{~Hz}$. Then, and because the local PI controller is used for a

(2) slide valve position, the servodistributors model can be reduced to two static relations defining the mass flow rates $q_{m^{p}}\left(u_{P}, p_{P}\right)$ and $q_{m^{v}}\left(u_{N}, p_{N}\right)$, where $u_{P}=u_{P c a l}$ and $u_{N}=u_{\text {Ncal }}$.

To establish a mathematical model of the power modulator flow stage, the standard ISO 6538 may be used, see for example Hildebrandt, Kharitonov, Sawdony, Göttert and Hartmann (2005). Another research work of Araki (1981) shows approximations based on physical laws by modeling the geometrical variations of the restriction areas of the servodistributor. Another way proposed by Richard and Scavarda (1996) is based on an experimental characterization model using a Wheatstone bridge representation of the servodistributor. Using the measures of the global experimental method giving the static characteristics of the flow stage, Belgharbi, Thomasset, Scavarda, and Sesmat (1999) has developed analytical models for both simulation and control purposes. For control purposes, the flow stage characteristics were approximated by the following model, affine in control, such that:

$$
q_{m(.)}=\varphi\left(p_{(.)}\right)+\psi\left(p_{(.)}, \operatorname{sgn}\left(u_{(.)}\right)\right) u_{(.)}
$$

Where $\varphi\left(p_{(.)}\right)$(fig. 5.a) in Eq.5 is a polynomial function of the pressure whose evolution corresponds to the mass flow rate leakage and does not depend of the input control. $\psi\left(p_{(\cdot)}, \operatorname{sgn}\left(u_{(.)}\right)\right)$is a polynomial function both of the pressure and the sign of the input control because the behavior of the mass flow rate characteristics is clearly different for the inlet $\left(u_{(.)}>0\right)$ (fig. 5.b) and the exhaust $\left(u_{(.)}<0\right)$ (fig. 5.c). The polynomial functions $\varphi\left(p_{(.)}\right), \psi\left(p_{(.)}, u_{(.)}>0\right), \psi\left(p_{(.)}, u_{(.)}<0\right)$ have been chosen with five equal degrees multi linear regression with $R^{2}$ (multiple correlation coefficients) greater than 0.96 .

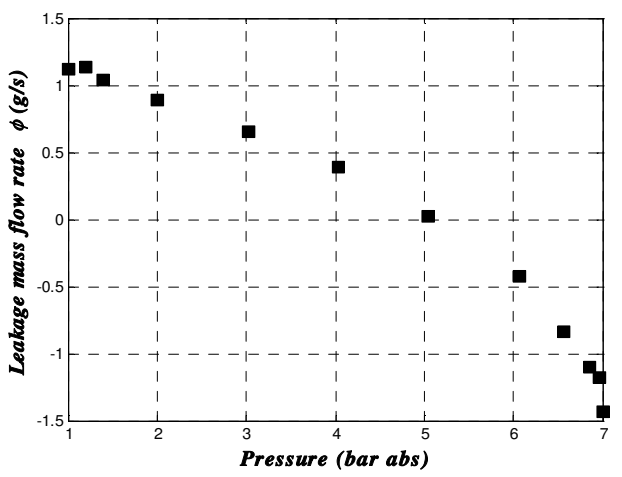

Fig. 5.a: The function $\varphi(p)$ 


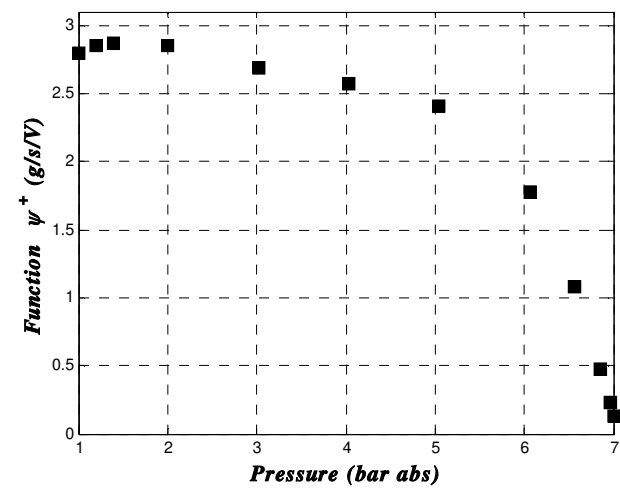

Fig. 5.b: The function $\psi(p, u>0)$

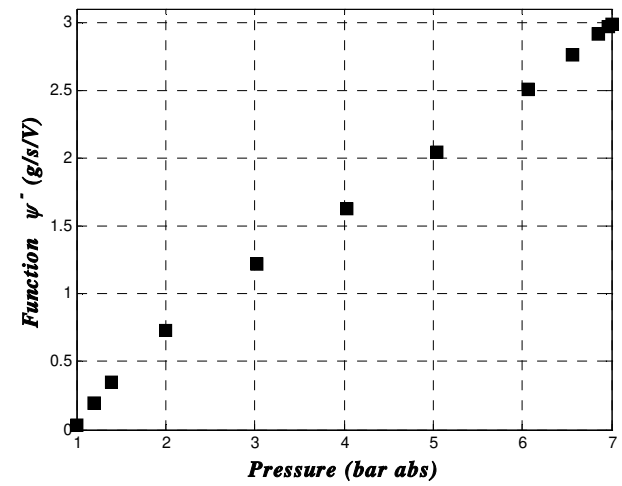

Fig. 5.c: The function $\psi(p, u<0)$

Using Eq.5 and Eq.2 with these two assumptions:

- $F_{s}$ and $F_{c}$ are not easily measurable and variable during experimental tests. Thus, only for the control model, the dry friction forces $F_{f}(v)$ in Eq.3, have been neglected compared to other forces,

- the temperature variation is negligible so the temperature chambers are equal to the supply temperature: $T_{P}=T_{N}=T_{s}$, with the polytropic coefficient $k=1.2$, see Shearer (1956).

The nonlinear affine model is then given by: $\dot{x}=f(x)+g(x) U$

Where $x=\left(y, v, p_{P}, p_{N}\right)^{T}$ and $D_{\varphi}$ is its physical domain:

$D_{\varphi}=\left[\begin{array}{ll}y_{\min } & y_{\max } \\ v_{\min } & v_{\max } \\ p_{p, \min } & p_{p, \max } \\ p_{n, \min } & p_{n, \max }\end{array}\right]=\left[\begin{array}{cc}-l / 2 & l / 2 \\ -v_{\max } & v_{\max } \\ P_{E}=10^{5} & P_{S}=7.10^{5} \\ P_{E}=10^{5} & P_{S}=7.10^{5}\end{array}\right]\left(\begin{array}{c}m \\ \mathrm{~m} / \mathrm{s} \\ \text { Pascal } \\ \text { Pascal }\end{array}\right)$
With

$$
f(x)=\left(\begin{array}{c}
v \\
\frac{1}{M}\left[S_{P} p_{P}-S_{N} p_{N}-b v-F_{e x t}\right] \\
\frac{k r T_{s}}{V_{P}(y)}\left[\varphi\left(p_{P}\right)-\frac{S_{P}}{r T_{s}} p_{P} v\right] \\
\frac{k r T_{s}}{V_{N}(y)}\left[\varphi\left(p_{N}\right)+\frac{S_{N}}{r T_{s}} p_{N} v\right] \\
0 \\
0 \\
\frac{k r T}{V_{P}(y)} \psi\left(p_{P}, \operatorname{sgn}\left(u_{P}\right)\right) \\
0 \\
0 \\
\frac{k r T}{V_{N}(y)} \psi\left(p_{N}, \operatorname{sgn}\left(u_{N}\right)\right)
\end{array}\right)
$$

In the next section a solution for the "stick-slip" problem of electropneumatic systems will be proposed.

\section{A solution for the "stick-slip" phenomenon of electropneumatic systems}

The problem of "stick-slip" was encountered with many other positions tracking control laws already applied to this electropneumatic system. Let us note for example, the backstepping control by Smaoui, Brun and Thomasset (2006a) and sliding mode control by Bouri and Thomasset (2001), Laghrouche, Smaoui, Plestan, and Brun (2006) and Smaoui, Brun and Thomasset (2008).

\subsection{Existence Condition of the "stick-slip" phenomenon}

When the partial equilibrium is attained $\left(\mathrm{t}=\mathrm{t}_{\text {stop }}\right.$ in figure 6), the condition (11) is satisfied, but the two pressures continue to evolve:

$$
\dot{v}=v=0 \Rightarrow F_{f}(0)=S_{P} p_{P}-S_{N} p_{N}-F_{e x t}
$$

However, according to Eq. 3:

$$
F_{f}(0)=\left[F_{C}+\left(F_{S}-F_{C}\right) \exp (c \times 0)\right] \operatorname{sign}(0)
$$

With the definition of sign function in Eq.4, the (7) "stick-slip" phenomenon is avoided (fig. 6) when this condition is satisfied:

$$
\begin{aligned}
F_{S}^{-} & \leq F_{f}(0) \leq F_{S}^{+} \\
F_{S}^{-}+F_{e x t} & \leq S_{P} p_{P}-S_{N} p_{N} \leq F_{S}^{+}+F_{e x t}
\end{aligned}
$$




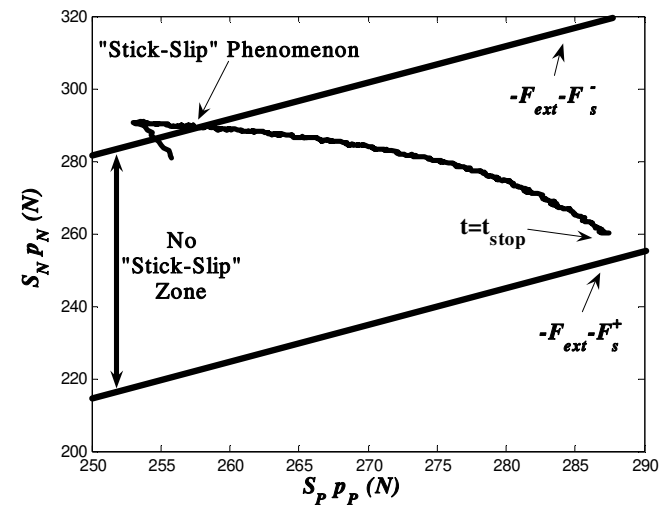

Fig. 6.a: "Stick-Slip" Phenomenon

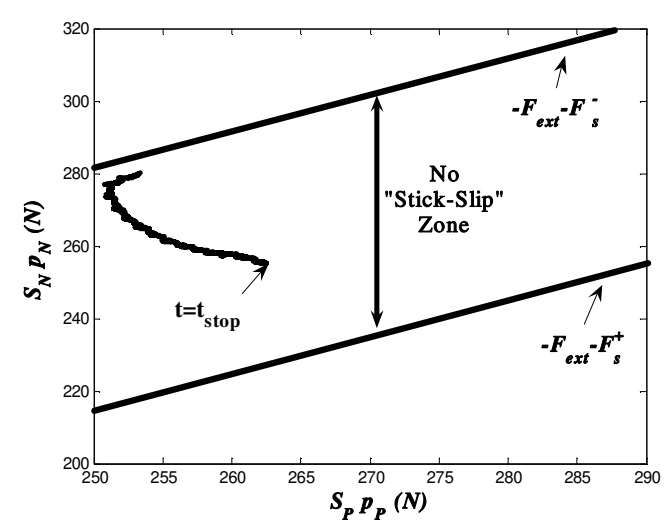

Fig. 6.b: No "Stick-Slip" Phenomenon

\subsection{Switching between position control and pressure regulation}

The system is controlled in position during the follow-up of trajectory and, if this trajectory contains a static phase, the closed-loop system switches to pressures regulation during this phase, according to the algorithm describes in next paragraph. Figure 7 illustrates the commutation between the control laws.

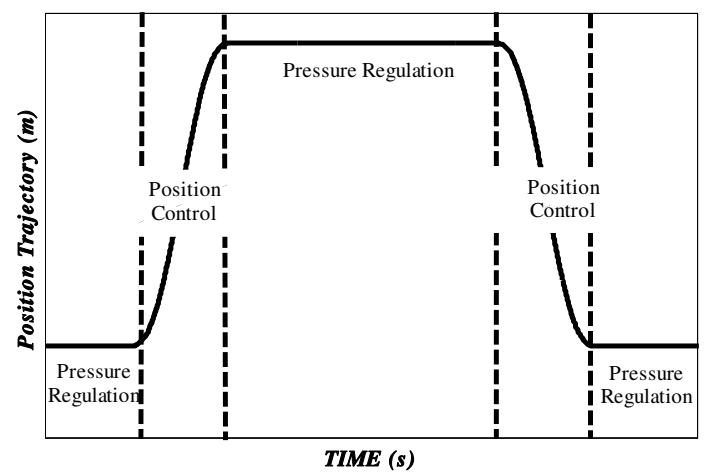

Fig. 7: Commutation between the control laws

The criterion of commutation chosen between these two control laws rests on error position and velocity variation. In fact the commutation of position control to pressure control is when all these conditions are satisfied:
1. $v_{d}=0:$ the desired velocity is null

2. $\left|y-y_{\text {stop }}\right| \leq \mathcal{E}_{1}$ : the position error during the static phase, lower than a value fixed in advance $\varepsilon_{1}$.

3. $|v| \leq \varepsilon_{2}$ : the velocity is very small. This last condition is necessary if the variation in the velocity desired trajectory is very important.

Initially the reference inputs of the regulation pressures $\left(p_{P}^{d}\right.$ and $\left.p_{N}^{d}\right)$ are the pressures values in the chamber when the system is at rest. Then, at any commutation, the reference inputs of the regulation pressures $\left(p_{P}^{d}\right.$ and $\left.p_{N}^{d}\right)$ are the pressure values in the chambers $\left(p_{P}^{\text {sop }}\right.$ and $\left.p_{N}^{\text {stop }}\right)$ which are maintained constant with these values. Figure 8 shows the time of calculation of the desired pressures and the selected values of its levels.

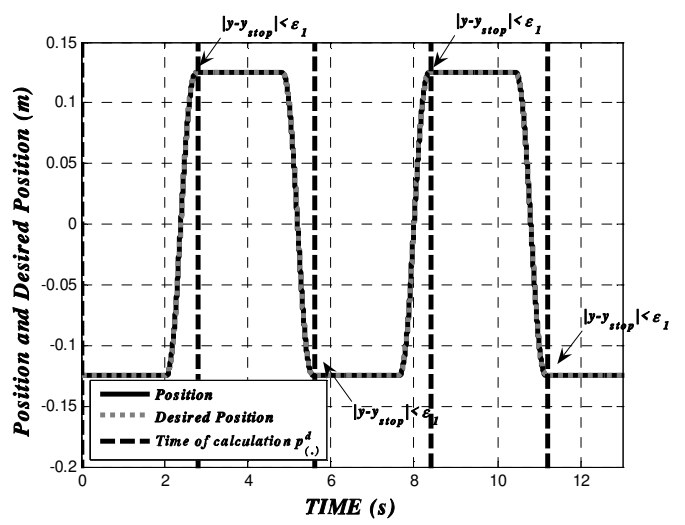

Fig. 8.a : Position \& Desired Position (m)

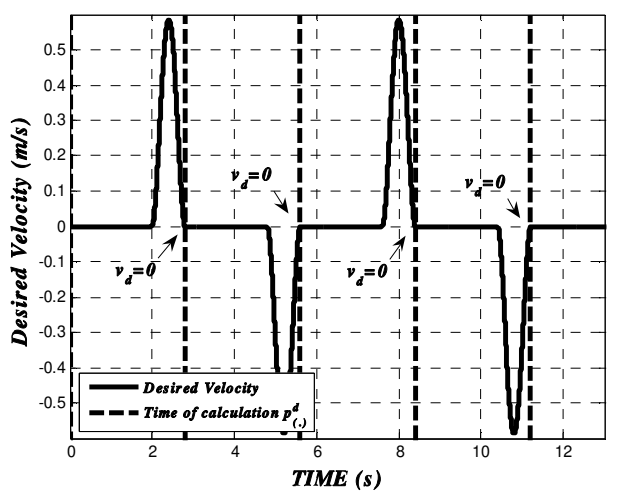

Fig. 8.b : Desired Velocity $(\mathrm{m} / \mathrm{s})$ 


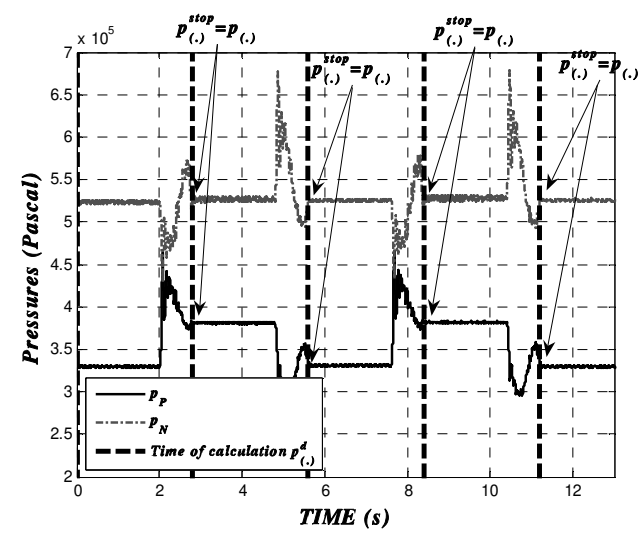

Fig. 8.c : Pressures (Pascal)

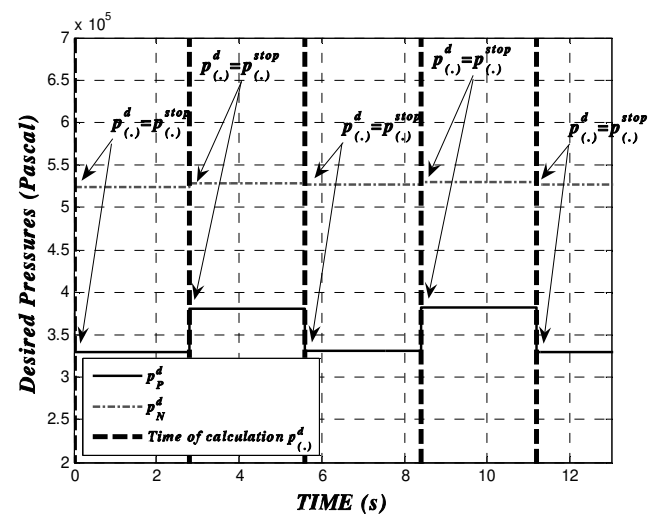

Fig. 8.d : Desired Pressures (Pascal)

For position tracking non linear control law is proposed and for the pressure control, the non linear input/output linearisation method is applied.

\subsection{Position control}

For the synthesis of the non linear tracking position control law, a diffeomorphism

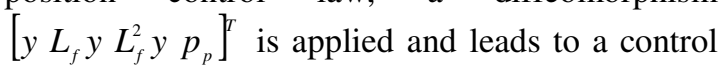
model of the form:

$$
\left\{\begin{aligned}
\dot{y} & =v \\
\dot{v} & =a \\
\dot{a} & =L_{f}^{3} y+L_{g} L_{f}^{2} y \cdot u \\
\dot{p}_{P} & =\frac{k r T_{s}}{V_{P}(y)}\left[\varphi\left(p_{P}\right)-\frac{S_{P}}{r T_{s}} p_{P} v\right]+\frac{k r T_{s}}{V_{P}(y)} \psi\left(p_{P}, \operatorname{sgn}(u)\right) u
\end{aligned}\right.
$$

where :

$$
u=u_{P}=-u_{N}
$$

and

$$
\begin{aligned}
L_{f}^{3} y\left(y, v, a, p_{P}, p_{N}\right)= & \frac{S_{p} k r T_{s}}{M V_{p}(y)}\left[\varphi\left(p_{P}\right)-\frac{S_{p}}{r T_{s}} p_{p} v\right]- \\
& \frac{S_{n} k r T_{s}}{M V_{n}(y)}\left[\varphi\left(p_{n}\right)+\frac{S_{n}}{r T_{s}} p_{n} v\right]-\frac{b}{M} a
\end{aligned}
$$

$$
\begin{aligned}
L_{g} L_{f}^{2} y\left(y, p_{P}, p_{N}\right)= & \frac{k r T_{s}}{M} \frac{S_{p} \psi\left(p_{p}, \operatorname{sign}(u)\right)}{V_{p}(y)}+ \\
& \frac{k r T_{s}}{M} \frac{S_{n} \psi\left(p_{n}, \operatorname{sign}(-u)\right)}{V_{n}(y)}
\end{aligned}
$$

As shown in figure (5.b and 5.c) $\psi_{(.)}>0$ and $L_{g} L_{f}^{2} y\left(y, p_{P}, p_{N}\right) \neq 0$ over the physical domain.

This system in Eq.14 is partially feedback linearizable. It has been shown in Brun, Belgharbi, Sesmat, Thomasset and Scavarda (1999) that the system is minimum phase.

Now create three separate dynamic errors as follow:

$$
\left\{\begin{array}{l}
e_{y}=y-y_{d} \\
e_{v}=v-v_{d} \\
e_{a}=a-a_{d}
\end{array}\right.
$$

And then a new state system:

The choice of input:

$$
u=\frac{1}{L_{g} L_{f}^{2} y}\left[-L_{f}^{3} y+\dot{a}_{d}-K_{a} e_{a}-K_{v} e_{v}-K_{y} e_{y}\right]
$$

leads to a linear closed loop system

$$
\left[\begin{array}{l}
\dot{e}_{y} \\
\dot{e}_{v} \\
\dot{e}_{a}
\end{array}\right]=\left[\begin{array}{ccc}
0 & 1 & 0 \\
0 & 0 & 1 \\
-K_{y} & -K_{v} & -K_{a}
\end{array}\right]\left[\begin{array}{l}
e_{y} \\
e_{v} \\
e_{a}
\end{array}\right]
$$

where the equilibrium point $\left[e_{y}=0 e_{v}=0 e_{a}=0\right]^{T}$ is exponentially stable $\forall K_{y}, K_{v}$ and $K_{a}$ and ensuring the Hurwitz polynomial $s+K_{a} s^{2}+K_{v} s+K_{y}=0$, see Isidori (1989).

\subsection{Pressure control}

For the pressure control, the classical non linear multi-input/multi-output linearisation method is used. In static phase, when the partial equilibrium is obtained, this system must be considered:

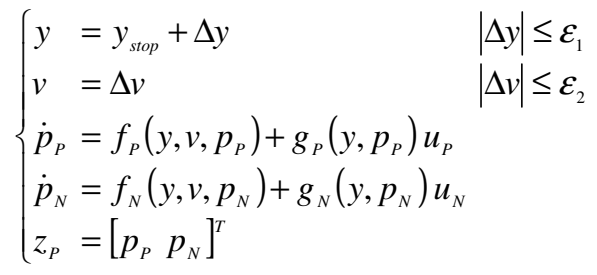


Where $\varepsilon_{1}$ and $\varepsilon_{2}$ are small and positive and :

$$
\begin{aligned}
f_{P}\left(y, v, p_{P}\right) & =\frac{k r T_{s}}{V_{P}(y)}\left[\varphi\left(p_{P}\right)-\frac{S_{P}}{r T_{s}} p_{P} v\right] \\
g_{P}\left(y, p_{P}\right) & =\frac{k r T_{s}}{V_{P}(y)}\left[\psi\left(p_{p}, \operatorname{sgn}\left(u_{P}\right)\right)\right] \\
f_{N}\left(y, v, p_{N}\right) & =\frac{k r T_{s}}{V_{N}(y)}\left[\varphi\left(p_{N}\right)+\frac{S_{N}}{r T_{s}} p_{N} v\right] \\
g_{N}\left(y, p_{N}\right) & =\frac{k r T_{s}}{V_{N}(y)}\left[\psi\left(p_{N}, \operatorname{sgn}\left(u_{N}\right)\right)\right]
\end{aligned}
$$

The outputs of the system are the two pressures.

Now create 2 separate errors between the pressure and the constant desired pressure:

$$
\left\{\begin{array}{l}
e_{P}=p_{P}-p_{P}^{d} \\
e_{N}=p_{N}-p_{N}^{d}
\end{array}\right.
$$

Differentiating each error Eq.23 once gives:

$$
\left\{\begin{array}{l}
\dot{e}_{P}=\dot{p}_{P}=f_{P}\left(y, v, p_{P}\right)+g_{P}\left(y, p_{P}\right) u_{P} \\
\dot{e}_{N}=\dot{p}_{N}=f_{N}\left(y, v, p_{N}\right)+g_{N}\left(y, p_{N}\right) u_{N}
\end{array}\right.
$$

Define the control inputs of system as:

$$
\left\{\begin{array}{l}
u_{P}=\frac{1}{g_{P}\left(y, p_{P}\right)}\left(-f_{P}\left(y, v, p_{P}\right)-k_{P} e_{P}\right) \\
u_{N}=\frac{1}{g_{N}\left(y, p_{N}\right)}\left(-f_{N}\left(y, v, p_{N}\right)-k_{N} e_{N}\right)
\end{array}\right.
$$

And combining Eq.25 into Eq.24:

$$
\left\{\begin{array}{l}
\dot{e}_{P}=-k_{P} e_{P} \\
\dot{e}_{N}=-k_{N} e_{N}
\end{array}\right.
$$

Therefore, since $k_{p}$ and $k_{N}>0, \quad e_{P}$ and $e_{N}$ converge exponentially to zero.

\section{$4 \quad$ Experimental Results}

Before the application on the real electropneumatic system, the method developed above was implemented in co-simulation. The co-simulation consists of using jointly the software developed by the modelling researchers, and the software dedicated for the system control. Thus, the physical model of electropneumatic system, defined in section 2.1, was treated by AMESim (LMS Imagine) and the control laws (Eq.19 and Eq.25), with the criteria of switching and the calculation of the desired pressure, were developed using Simulink Mathworks. In fact the cosimulation enables the parameters of the commutation criterion and the gains of the two control laws to be tested. Satisfactory simulation results are obtained.
Then the control law is implemented using a Dspace 1104 controller board with the dedicated digital signal processor. The controller requires measurements of position, velocity, acceleration and the two pressures. The measured signals, all analog, were run through the signal conditioning unit before being read by the 16 bit analog/digital converter. Two pressure sensors are used, their precision is equal to $700 \mathrm{~Pa}(0.1 \%$ of the extended measurement) and their combined non linearity and hysteresis is equal to $0.1 \%$ of the extended measurement. The cylinder velocity is determined by analogue differentiation and low-pass filtering of the output of the position given by an analogue potentiometer (Its precision and repeatability is equal to $10 \mu \mathrm{m}$ and its linearity is $0.05 \%$ of the extended measurement.). The acceleration information is obtained by a robust velocity differentiator, via a high order sliding mode; see Smaoui, Brun and Thomasset (2008).

\subsection{An Example of the "stick-slip" phenomenon}

For the first part of these experimental results an example of the "stick slip" phenomenon is explained. This is shown on a position tracking system with only one control law (i.e. without commutation between position tracking and pressures regulation).

Figure 9 shows the "stick-slip" phenomenon with the position, the desired position, the position error, the pressure in the chambers $\mathrm{P}$ and $\mathrm{N}$, the control input and the "stick-slip" phenomenon. For this position tracking the gains are fixed to $K_{y}=96000, K_{v}=6800, K_{a}=150$. For a total displacement equal to $250 \mathrm{~mm}$, the maximum dynamic position tracking error is about $1.5 \mathrm{~mm}$. In, a steady state, the average position error is about $0.13 \mathrm{~mm}$. The pressures continue to evolve, during the steady state of the position. The "stickslip' phenomenon is seen at $t=31 \mathrm{~s}$, $t=33,4 s$ and $t=34,2 s$.

On the same experimental set-up and in the same conditions, has been implemented two other non linear control laws:

- a backstepping control in Smaoui, Brun and Thomasset $(2006 \mathrm{~b})$ the error in steady sate is about $0.10 \mathrm{~mm}$.

- an high order sliding mode controller in Smaoui, Brun and Thomasset (2006 b) the error in steady sate is about $0.11 \mathrm{~mm}$.

With these two control laws, the "stick slip" problem also appears. Thus the tracking performances obtained by the control proposed are similar in regard of precedents one. 


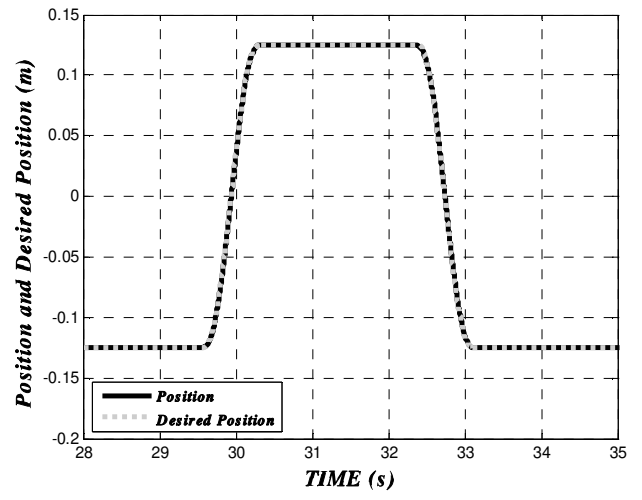

Fig. 9.a :Position \& Desired Position (m)

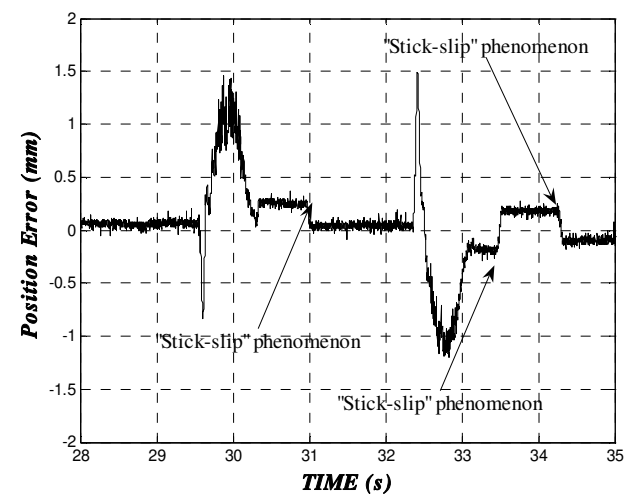

Fig. 9.b : Position Error (mm)

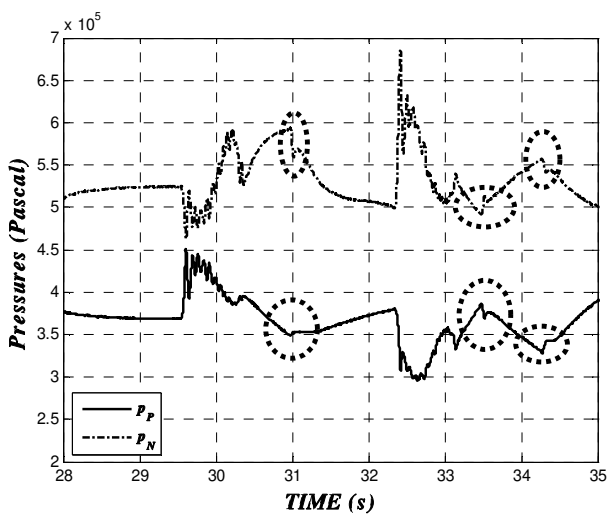

Fig. 9.c : Pressures (Pascal)

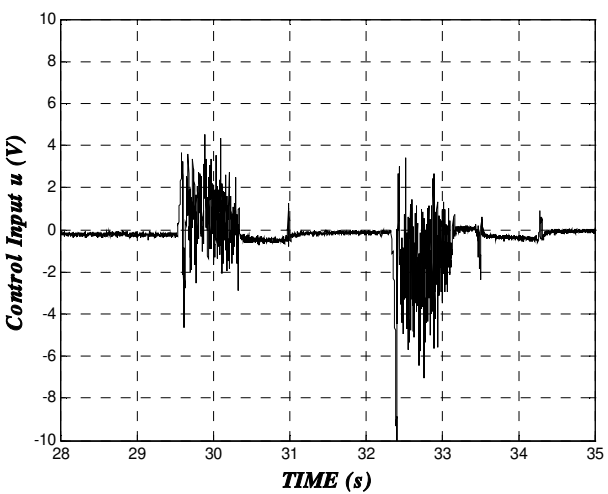

Fig. 9.d : Control input (V)

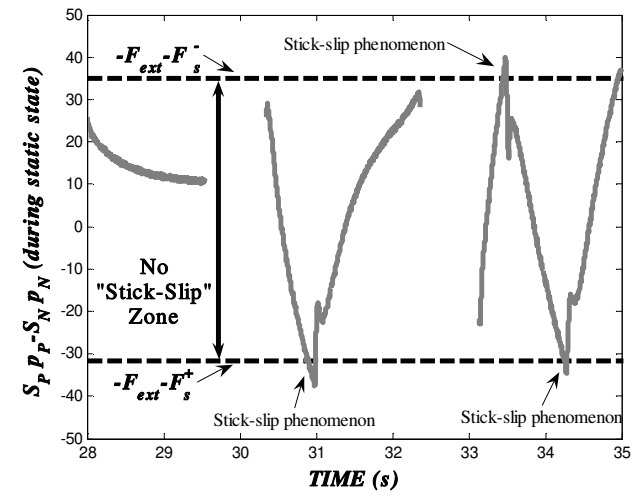

Fig. 9.e : "Stick-slip" phenomenon

\subsection{An example of a no "stick-slip" phenomenon}

In the second part of this section, the experimental results are presented when the system is controlled by the two control laws developed in section 3.2 and 3.3 with the commutation criteria proposed in section 3.1, position control during the dynamic phase and pressure regulation during the static phase. Thus fig. 10 proves that the solution proposed avoids the "stick-slip" phenomenon.

For the position control the gains tuned are the same that in last section. For the pressure control the gains are fixed to $k_{p}=k_{N}=300$. These values ensure good static and dynamic performances. Some experimental results are provided here to demonstrate the validity of the solution suggested to the problem of "stick-slip".

Figure 10 shows the position, the desired position same that it's shown in fig. 9.a, the position error, the pressure in the chamber $\mathrm{P}$, the pressure in the chamber $\mathrm{N}$, the control inputs $u_{P}$ and $u_{N}$ and no "stick-slip" phenomenon. The maximum dynamic position tracking error is about $1.65 \mathrm{~mm}$. In steady state, the average position error is about $0.18 \mathrm{~mm}$.

The presence of thresholds on the criteria of commutation degrade a little the performances compared to the preceding case but the pressures are stabilized during this static phase of the position and the phenomenon of "stick-slip" is avoided. 


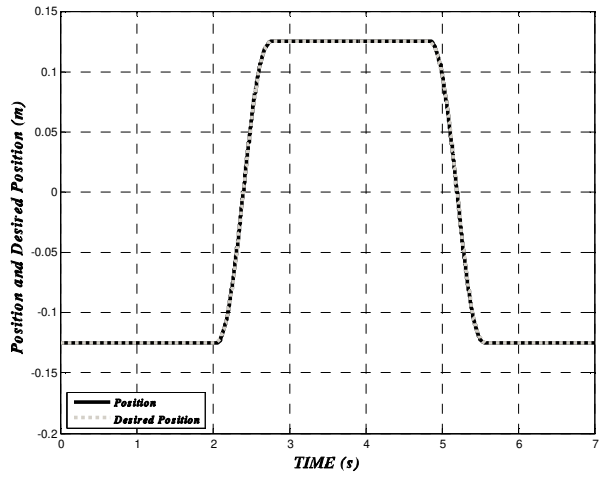

Fig. 10.a :Position \& Desired Position (m)

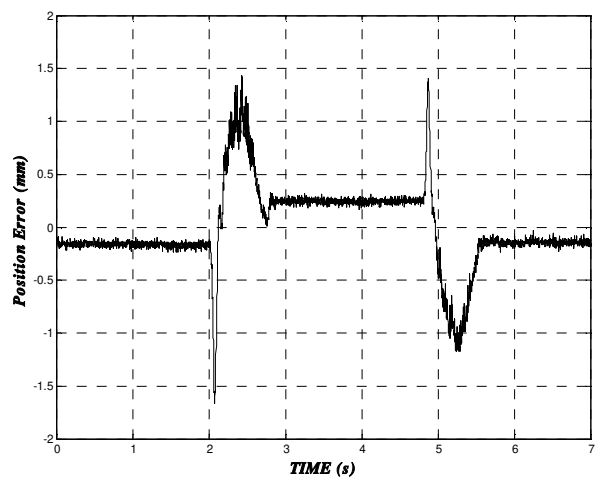

Fig. 10.b : Position Error (mm)

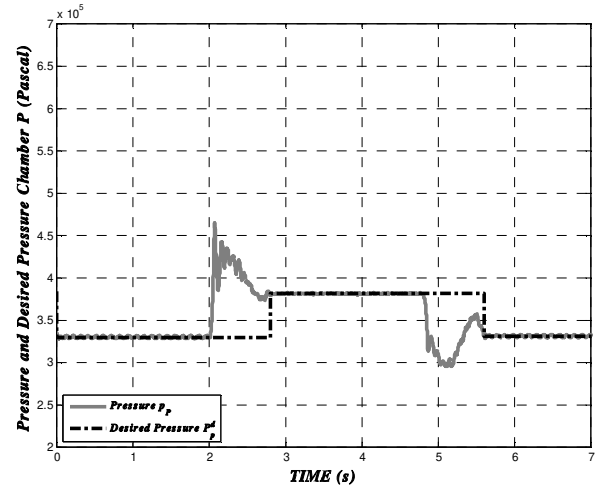

Fig. 10.c : Pressure and desired pressure chamber $P$ (Pascal)

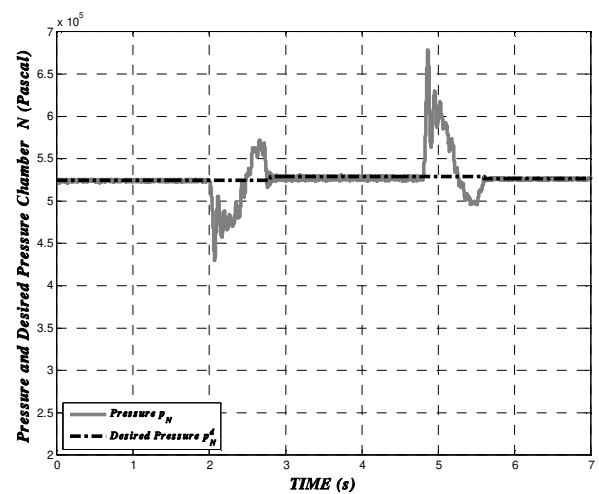

Fig. 10.d : Pressure and desired pressure chamber N (Pascal)

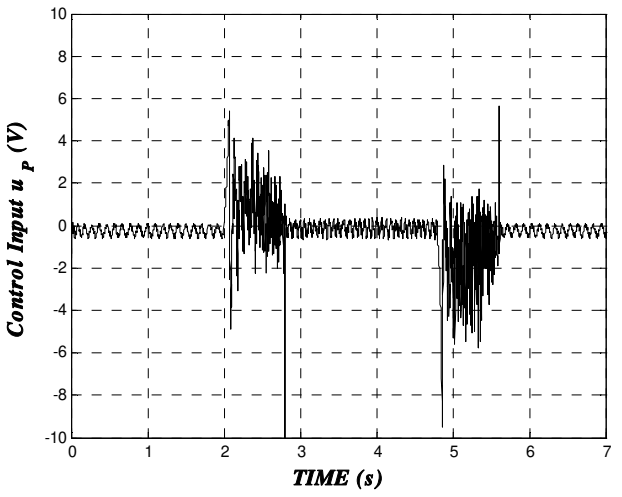

Fig. 12.e : Control input $u_{P}$ (V)

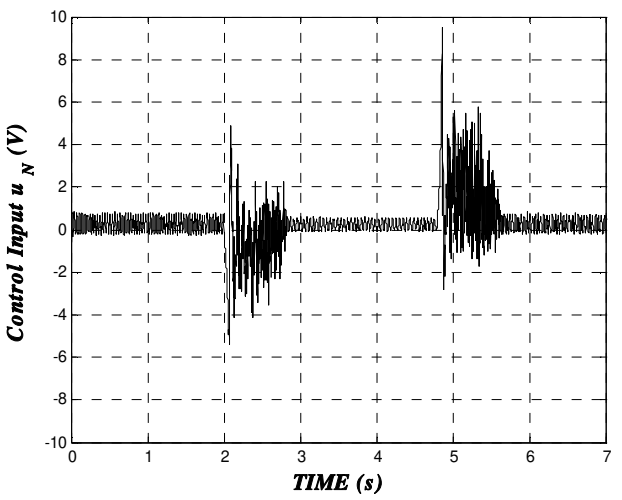

Fig. 12.f : Control input $u_{N}$ (V)

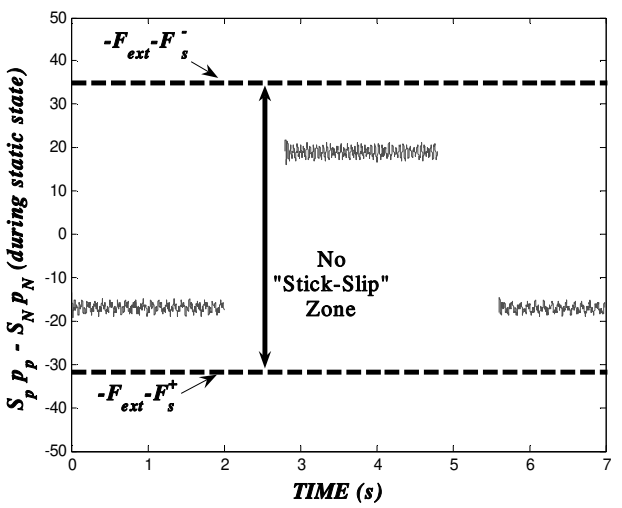

Fig. 10.g : No "stick-slip" phenomenon

\section{$5 \quad$ Conclusion}

The contribution of this paper consists of the solution to the "stick-slip" phenomenon for an electropneumatic system with a given desired position trajectory. The system is controlled by two sets of control laws, a non linear control law for the dynamic state of the position then, when the system is in partial equilibrium, the algorithm switches to the pressure regulations obtained with the classical non linear input/output linearization method.

The perspectives are to avoid the "stick-slip" phenomenon, without degrading the performances of tracking position trajectory. 


\section{Nomenclature}

$b \quad$ viscous friction coefficient $(\mathrm{N} / \mathrm{m} / \mathrm{s})$

$k \quad$ polytropic constant

$M \quad$ total load mass (kg)

$p \quad$ pressure in the cylinder chamber (Pascal)

$q_{m}$ mass flow rate provided from servodistributor to cylinder chamber $(\mathrm{kg} / \mathrm{s})$

$r \quad$ perfect gas constant related to unit mass $(\mathrm{J} / \mathrm{kg} / \mathrm{K})$

$S \quad$ area of the piston cylinder $\left(\mathrm{m}^{2}\right)$

$T_{s} \quad$ temperature $(\mathrm{K})$

$V \quad$ volume $\left(\mathrm{m}^{3}\right)$

$y \quad$ position $(\mathrm{m})$

$v \quad$ velocity $(\mathrm{m} / \mathrm{s})$

$a \quad$ acceleration $\left(\mathrm{m} / \mathrm{s}^{2}\right)$

$\varphi$ (.) polynomial leakage function $(\mathrm{kg} / \mathrm{s})$

$\psi($.) polynomial function $(\mathrm{kg} / \mathrm{s} / \mathrm{V})$

$l \quad$ length of stroke $(\mathrm{m})$

$F_{\text {ext }} \quad$ External force $(\mathrm{N})$

$F_{f} \quad$ dry friction force $(\mathrm{N})$

$F_{c} \quad$ Coulomb friction $(\mathrm{N})$

$F_{s} \quad$ Stiction friction $(\mathrm{N})$

$c \quad$ Stribeck effect constant

$x \quad$ slide valve position

$u, u_{(.)} \quad$ control input

\section{Subscript and superscript}

$\begin{array}{ll}D & \text { dead volume } \\ N & \text { chamber } \mathrm{N} \\ P & \text { chamber } \mathrm{P} \\ d & \text { Desired } \\ \text { max } & \text { maximum }\end{array}$

\section{REFERENCES}

Araki, K. 1981. Effects of valve configuration on a pneumatic servo. $6^{\text {th }}$ International Fluid Power Symposium, Cambridge U.K, Paper F2, pp. 271290.

Belgharbi, M., Thomasset, D., Scavarda, S. and Sesmat, S. May 26-28 1999. Analytical model of the flow stage of a pneumatic Servodistributor for simulation and nonlinear control. The Sixth Scandinavian International Conference on Fluid Power, SICFP, Tampere, Finland, pp. 847-860.

Bouri, M. and Thomasset, D. 2001. Sliding control of an electropneumatic actuator using an integral switching surface. IEEE Transactions on control systems technology, Vol. 9. $\mathrm{n}^{\circ} 2$, pp. 368375.

Brun, X., Belgharbi, M., Sesmat, S., Thomasset, D. and Scavarda, S. 1999. Control of an electropneumatic actuator, comparison between some linear and nonlinear control laws. Journal of Systems and Control Engineering, Vol. 213, $\mathrm{n}^{\circ} 15$, pp. 387-406.
Brun, X., Sesmat, S., Thomasset, D. and Scavarda, S. March 2005. Study of "sticking and restarting phenomenon" on electropneumatic positioning systems. Journal of Dynamic Systems, Measurement and Control, Vol. 127, pp. 173-184.

Control Engineering Staff. 2003. Servo Pneumatics Finding its Niche, Bit by Bit. Control Engineering Europe. pp. 32-33.

Isidori, A. 1989. Nonlinear Control Systems. Second Edition. Communications and Control Engineering Series. Springer, 479 p.

Hägglund, Tore. October 2002. A friction compensator for pneumatic control valves. Journal of Process Control, Vol. 12, $\mathrm{n}^{\circ} 8$, pp. 897-904.

Hamiti, K., Voda-Besancon, A. and RouxBuisson, H. August 1996. Position control of a pneumatic actuator under the influence of stiction. Control Engineering Practice, Vol. 4, n'8, pp. 1079-1088.

Hildebrandt, A., Kharitonov, A., Sawdony, O., Göttert and Hartmann, A. 2005. On the zero dynamic of servo pneumatic actuators and its usage for trajectory planning and control. IEEE International Conference on Mechatronics \& Automation, Niagara Falls, Canada, pp. 12411246.

Laghrouche, S., Smaoui, M., Plestan, F. and Brun, X. 2006. Higher order sliding mode control based on optimal approach of an electropneumatic actuator. International Journal of Control, Vol. 79, n², pp. 119-131.

Ming-Chang, S. and Shy-I, T. 1995. Identification and Position Control of a Servo Pneumatic Cylinder. Control Engineering Practice, Vol. 9. pp. 1285-1290.

Pai, K.R. and Shih, M.-C. September 2003. Nanoaccuracy position control of a pneumatic cylinder driven table. JSME International Journal, Series C: Mechanical Systems, Machine Elements and Manufacturing, Vol. 46, $\mathrm{n}^{\circ} 3$, pp. 1062-1067.

Renn, J.-C., Liao, C.-M. 2004. A study on the speed control performance of a servo-pneumatic motor and the application to pneumatic tools. International Journal of Advanced Manufacturing Technology, Vol. 23, n 7-8, pp 572-576.

Richard, E. and Scavarda, S. 1996. Comparison between linear and nonlinear control of an electropneumatic servodrive. Journal of Dynamic Systems, Measurement, and Control. Vol. 118, pp. 245-252.

Sesmat, S. and Scavarda, S. 1996. Static characteristics of a three way servovalve. 12th Aachen Conference on Fluid Power Technology, Aachen, Germany, pp. 643-652.

Shearer, J.L. 1956. Study of pneumatic processes in the continuous control of motion with 
compressed air. Parts I and II. Transactions of the American Society of Mechanical Engineers, Vol. 78, pp. 233-249.

Smaoui, M., Brun, X. and Thomasset, D. 2006a. A study on tracking position control of an electropneumatic system using backstepping design. Control Engineering Practice, Vol. 14, n 8, pp. 923-933.

Smaoui, M., Brun, X. and Thomasset, D. 2006 b. Systematic Control of an Electropneumatic System: Integrator Backstepping And Sliding Mode Control. IEEE Transaction on Control System Technology, Vol.14, n5, pp. 905-913.

Smaoui, M., Brun, X. and Thomasset, D. 2008. High Order Sliding Mode for an Electropneumatic System: A DifferentiatorControllers Design. International Journal of Robust and Nonlinear Control, Vol. 18, pp. 481501.

Tustin, A. 1947. The effect of backlash and speeddependent friction on the stability of closed-cycle control systems. Journal of the Institution of Electrical Engineers, Vol. 94, pp. 143-151.

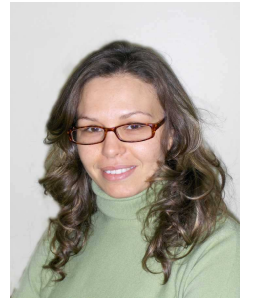

\section{Karima TURKI}

was born in Mahdia, Tunisia, in 1978. She obtained the academic degree of National Engineering Diploma and the M.Sc. degree, with specialization in control and computer engineering, at the National Institute of Applied Sciences and Technology INSAT, Tunis, in 2003 and 2004 respectively. In September 2006 She started a PhD studies at National Institute of Applied Sciences, Lyon, France. His research interests include advanced control of mechanical systems.

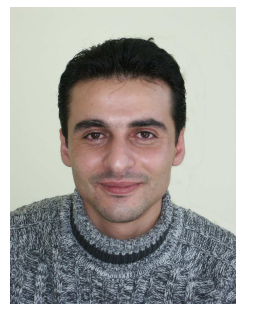

\section{Mohamed SMAOUI}

was born in Sfax, Tunisia, in 1976. He received the electrical engineering degree from the National Engineering School of Sfax, Sfax, Tunisia, in 2000, and the M.Sc. and D.Sc. degrees in automation from the Institut National des Sciences Appliquiées de Lyon (INSA), Lyon, France, 2001 and 2004, respectively. He has been an Associate Professor at the Department of Mechanical Engineering at INSA, since 2005. His research interests include advanced control of mechanical systems.

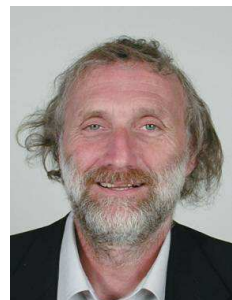

\section{Daniel THOMASSET}

Engineer (1972) in Electrical Engineering (option Control), $\mathrm{PhD}$ (1978) and "Doctorat d'Etat français" (1987). He is currently Professor at the National Institute of Applied Sciences, Lyon, France and Researcher at the AMPERE Laboratory (UMR 5005 CNRS, France). His research interests include control and sizing of Mecatronics systems especially Fluid Power systems. He obtain (2001), with R. Fotsu Ngwompo and S. Scavarda, the Donald Julius Price of the Institution of Mechanical Engineers, U. K., for their work on sizing described in the paper "Physical model-based inversion in control systems design using Bond Graph representation", Proceedings of ImechE, Part I: Journal of Systems and Control Engineering, vol 15, $n^{\circ} 12,2001$.

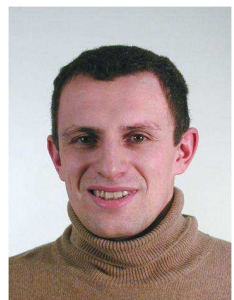

\section{Xavier Brun}

was born in France in 1973. He is $\mathrm{PhD}$ graduate from INSA Lyon Scientific and Technical University in 1999. From 2001 to 2006, Dr Brun was associate professor at Laboratoire d'Automatique Industrielle (LAI) in France. Since 2007 is head of Control team at Ampere Laboratory in INSA of Lyon in France. His current interests concerns the developpement and control of fluid power actuators. 